Document downloaded from:

http://hdl.handle.net/10251/64683

This paper must be cited as:

Ribadeneira Ramírez, JA.; Martínez, G.; Gómez Barquero, D.; Cardona, N. (2016). Interference Analysis Between Digital Terrestrial Television (DTT) and 4G LTE Mobile Networks in the Digital Dividend Bands. IEEE Transactions on Broadcasting. 62(1):24-34. doi:10.1109/TBC.2015.2492465.

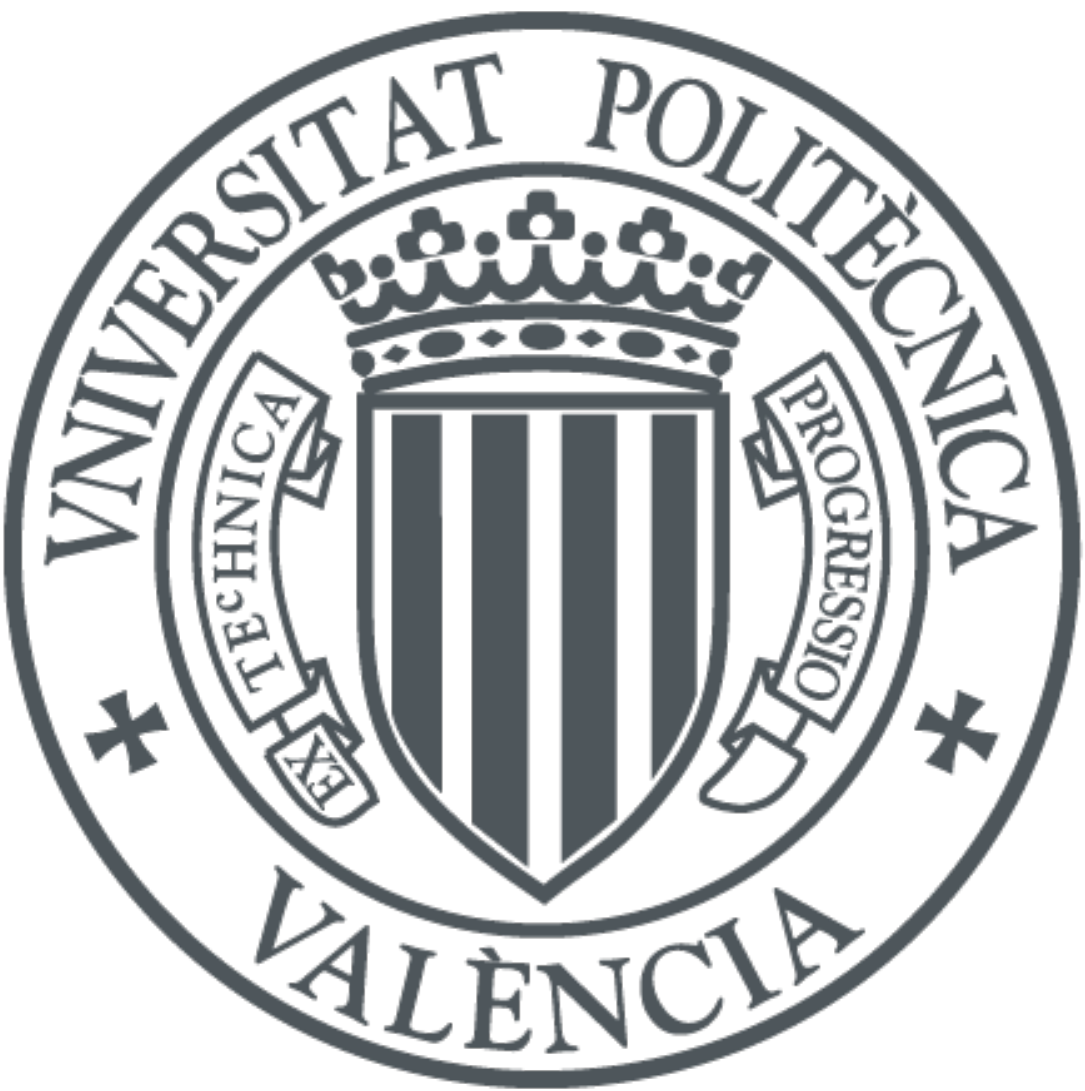

The final publication is available at

http://dx.doi.org/10.1109/TBC.2015.2492465

Copyright Institute of Electrical and Electronics Engineers (IEEE)

Additional Information 


\title{
Interference Analysis between Digital Terrestrial Television (DTT) and 4G LTE Mobile Networks in the Digital Dividend Bands
}

\author{
Jefferson Ribadeneira-Ramírez, Gerardo Martínez, David Gomez-Barquero, Narcís Cardona
}

\begin{abstract}
With the introduction of Digital Terrestrial Television (DTT) and the analogue television switch-off, terrestrial broadcast spectrum in the UHF band is being released for mobile communications, in particular for fourth generation (4G) Long Term Evolution (LTE) mobile services. This spectrum is known as digital dividend. An impending problem when deploying 4G LTE mobile networks in the digital dividend bands is that interferences may appear in the adjacent radio frequency channels used for DTT. In this paper, we analyze the adjacent coexistence of DTT and 4G LTE networks in the digital dividend bands at $700 \mathrm{MHz}$ and $800 \mathrm{MHz}$. A generic framework is adopted such that results can be easily extrapolated to different scenarios and bands. Results are presented as a function of the guard band between technologies, for both LTE uplink and downlink adjacent to the DTT signals, and for fixed outdoor and portable indoor DTT reception. Also, the effect of using anti-LTE filters is studied.

Index Terms - 4G, ATSC, digital dividend, digital terrestrial television, DVB-T2, interference, ISDB-Tb, LTE, RF spectrum, transmission scenario, anti-LTE filters, coexistence.
\end{abstract}

\section{INTRODUCTION}

$\mathrm{O}$ NE of the key discussions on spectrum demand to enable the future mobile landscape is the feasibility of allocating more spectrum for mobile broadband use. With the introduction of Digital Terrestrial Television (DTT) and the analogue switch-off, spectrum traditionally used for terrestrial broadcasting in the UHF (Ultra-High Frequency) band from $470 \mathrm{MHz}$ to $862 \mathrm{MHz}$ has been released for cellular mobile systems. This band is technically better suited to achieve widespread mobile coverage outside of the main urban areas due to its excellent propagation characteristics. The spectrum released is known as Digital Dividend (DD) [1].

From a spectrum organization point of view, the world is divided in three regions by the International Telecommunications Union (ITU): Region 1 (Europe and Africa), Region 2 (Americas) and Region 3 (Asia and Oceania). The first DD band (DD1), which is the amount of spectrum made available after the transition from analogue to digital terrestrial TV broadcasting, corresponds to the 800

Manuscript received June 8, 2015; reviewed September 10, 2015; accepted September 24, 2015. This work was supported in part by the spectrum regulator of Colombia ANE (Agencia Nacional del Espectro).

The authors are with the iTEAM Research Institute, Universitat Politecnica de Valencia, 46022 Valencia, Spain (email: \{jefrira, gemarpin, dagobar, ncardona\}@iteam.upv.es).
$\mathrm{MHz}$ band (from 790 to $862 \mathrm{MHz}$ ) in Regions 1 and 3, and the $700 \mathrm{MHz}$ band (from 698 to $806 \mathrm{MHz}$ ) in Region 2, see Fig._1.

Most spectrum regulators worldwide have already auctioned and awarded the DD1 band to fourth generation (4G) Long Term Evolution (LTE) mobile services. In Europe, some countries such as Finland, Germany, Sweden and UK have already announced their intentions to allocate the 700 $\mathrm{MHz}$ band to mobile services by performing a second digital dividend (DD2), some countries as early as 2017 [2], and it is

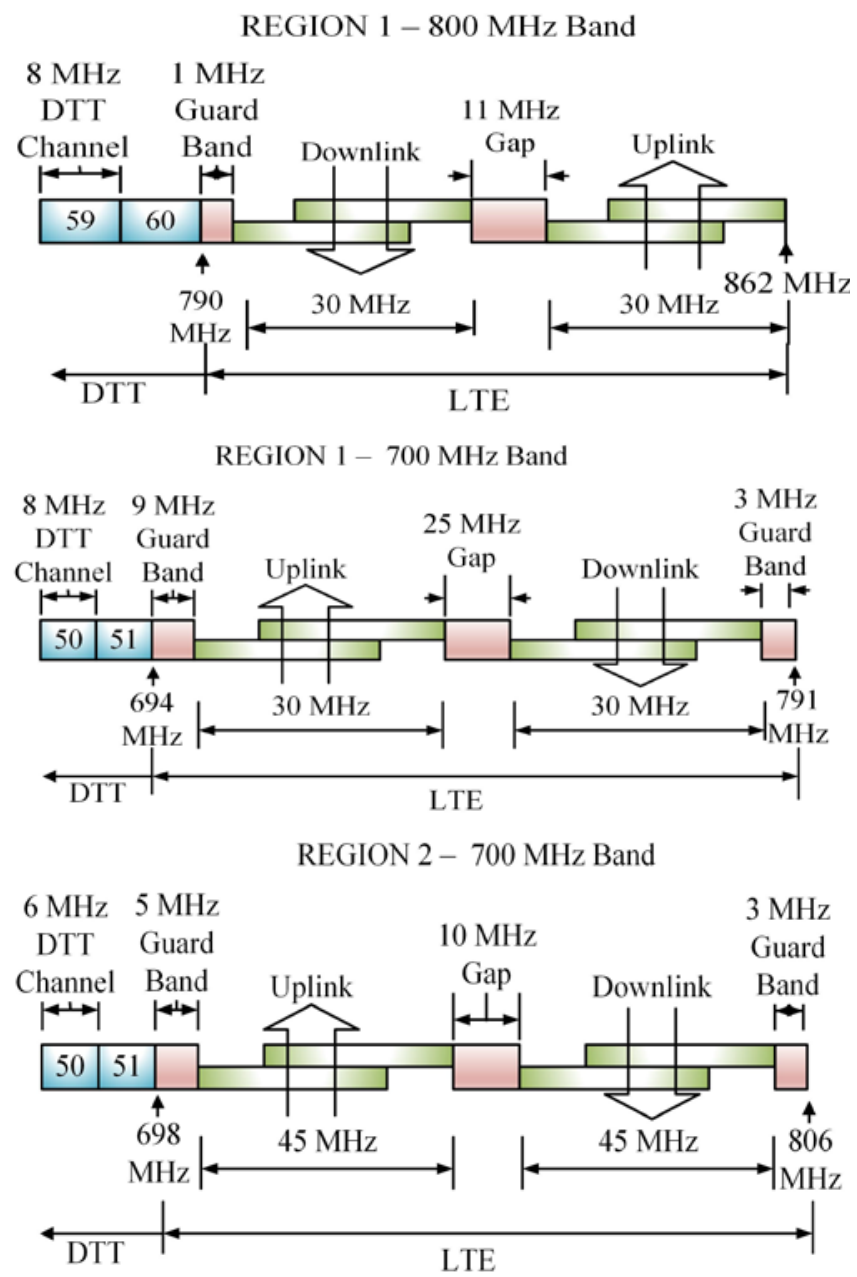

Fig. 1. Preferred harmonized 4G LTE channeling arrangement for ITU Region 1 at $800 \mathrm{MHz}$ band (top), for Region 1 at $700 \mathrm{MHz}$ band (middle) and for Region 2 at $700 \mathrm{MHz}$ band (bottom). 
expected that an harmonized DD2 will take place in Europe around the horizon 2020 [3]. On the other side of the Atlantic, the U.S. is taking a further step by considering the $600 \mathrm{MHz}$ band as a DD2 [4].

An impending problem when deploying mobile networks in the digital dividend bands is that interferences may appear in the adjacent radio frequency (RF) channels used for DTT. Possible solutions imply either an inefficient use of the spectrum, increasing the guard band and reducing the number of RF channels for DTT, or an important cost using anti-LTE filters for DTT receivers [5]. The guard band in the $800 \mathrm{MHz}$ band is only $1 \mathrm{MHz}$, whereas in Region 2 the guard band in the $700 \mathrm{MHz}$ band is $5 \mathrm{MHz}$. However, in the $800 \mathrm{MHz}$ band the LTE downlink (DL) is located in the lower part of the band instead of the uplink (UL), as traditionally done for cellular networks, and adopted for the $700 \mathrm{MHz}$ band plan. Since cellular terminals may be closer to DTT receivers than cellular base stations, interference issues are more critical, and that is the reason why in Europe it has been proposed to use 9 $\mathrm{MHz}$ guard band.

The coexistence problems between DTT and 4G LTE have been mostly addressed by standardization and regulatory entities. Regarding the $800 \mathrm{MHz}$ band in Europe, reference [6] presents generic requirements for the coexistence between DVB-T and LTE for different outdoor and indoor scenarios. In [7] and [8] it was concluded that an external filter, between the TV antenna and the DTT receiver is required when the DTT receiver is near to the LTE base station. In [9], [10] and [11], it was shown that the performance of the broadcast technology (DVB-T, DVB-T2 and T2-Lite) can be seriously affected by an adjacent LTE signal without any guard band in-between. LTE interference Protection Ratios (PR) for DVB-T (Digital Video Broadcast - Terrestrial) and DVB-T2 (Terrestrial $2^{\text {nd }}$ Generation) can be found in [12] and [13], respectively.

Regarding the coexistence analysis in the $700 \mathrm{MHz}$ band, reference [14] presents generic requirements for the coexistence between DVB-T/T2 and LTE for fixed outdoor and portable indoor DTT reception using Monte Carlo systemlevel simulations. Coexistence studies for other DTT technologies can be found in [15] for DVB-T2, [16] for ATSC (Advanced Television Systems Committee), [17] and [18] for ISDB-T (Integrated Services Digital Broadcasting Terrestrial), and [19] for DTMB (Digital Terrestrial Multimedia Broadcast). Reference [20] compares the maximum out-of-band (OOB) emission levels for the LTE user equipment (UE) proposed by different entities applied to the European scenario.

Most results available in the literature are in general very specific, and specific use cases and scenarios are considered (e.g., for a given guard band, DTT transmission mode, etc.). Hence, results cannot be easily extrapolated to different scenarios. In this paper, we investigate adjacent coexistence issues between DTT and 4G LTE in the digital dividend bands, using laboratory measurements and link budget analysis. A generic framework is adopted such that results can be easily extrapolated to different scenarios and bands. Results are presented as a function of the guard band between

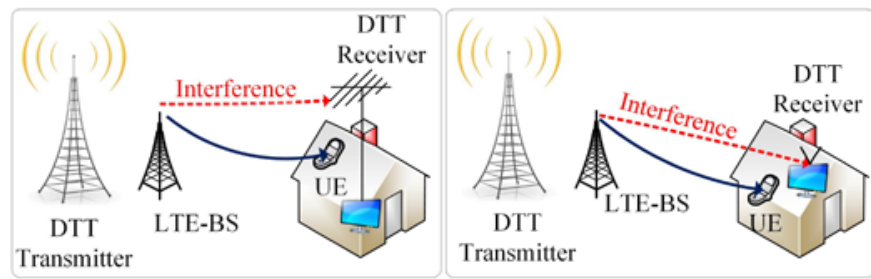

(a)

(b)

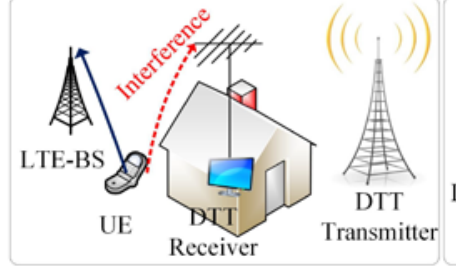

(c)

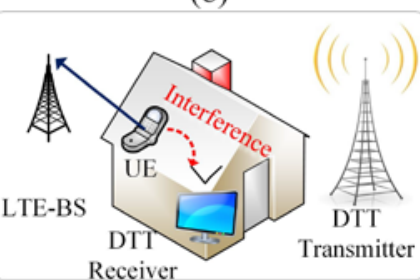

(d)
Fig. 2. Critical coexistence scenarios for LTE-DL (top) and LTE-UL (bottom) for fixed outdoor (left) and portable indoor (right) DTT reception.

technologies, for both LTE uplink and downlink adjacent to the DTT signals, and for fixed outdoor and portable indoor DTT reception. Also, the effect of using anti-LTE filters is studied. Results are presented for DVB-T2 technology [21], the current state-of-the art DTT technology worldwide. The results in this paper are also applicable to other OFDM-based DTT technologies such as DVB-T, ISDB-T, DTMB, or even the future ATSC 3.0 standard [22]. The results in this paper are relevant for broadcasters, mobile operators and also for regulatory entities.

The rest of the paper is structured as follows. The coexistence scenarios are presented in Section II. Section III describes the methodology followed. Section IV presents the measurement results of interference protection ratios. Section $\mathrm{V}$ discusses the coexistence of DTT and LTE in the $800 \mathrm{MHz}$ in Europe. Section VI analyzes the coexistence in the 700 $\mathrm{MHz}$ band. Finally, Section VII concludes the paper.

\section{Coexistence Scenarios FOR DTT AND 4G LTE}

The coexistence scenarios can be mainly classified depending on the type of LTE interfering link: Uplink (LTEUL) or Downlink (LTE-DL), and the DTT reception type: fixed outdoor, portable indoor, or mobile. Fig. 2 depicts the worst coexistence cases, which imply that the DTT receiver is at the edge of the coverage area, receiving the useful DTT signal just above threshold.

When the LTE-DL is the interfering link, the worst case is when the LTE base station (LTE-BS) is close to the DTT rooftop antenna, and oriented in the same direction than the TV station. The portable indoor DTT reception scenario is not as critical as the fixed outdoor reception, because the interfering signal experiences an additional building penetration loss.

When the LTE-UL is the interfering link, the worst case for fixed rooftop DTT reception is when the LTE user equipment (LTE-UE) is outdoors and relatively close (assuming $10 \mathrm{~m}$ antenna height, the worst-case distance is $22 \mathrm{~m}$ taking into account the vertical discrimination of DTT receiver antenna [14]) and in Line-of-Sight (LoS) with the DTT antenna. For portable indoor DTT reception, the worst case is when the 
TABLE I

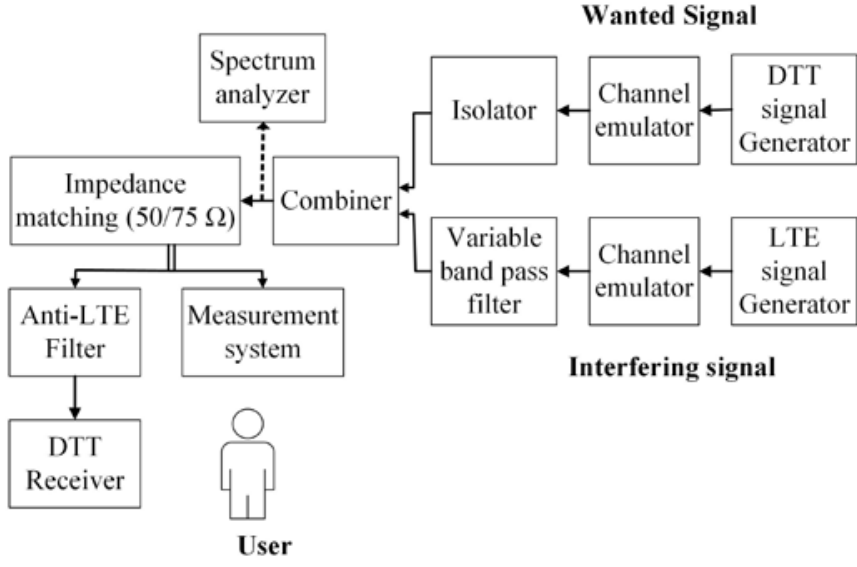

Fig. 3. Experimental laboratory set-up to measure interference protection ratios between DTT and 4G LTE signals.

LTE-UE is in the same room than the DTT. In these scenarios, the worst-case implies that the LTE-UE transmits with the maximum possible power $(23 \mathrm{dBm})$.

\section{METHODOLOGY}

The evaluation methodology followed in this paper consists in two different parts. First, interference protection ratios are measured in laboratory conditions. Second, link budget analyses are derived in order to assess the maximum 4G LTE interference levels on DTT signals in the worst-case coexistence scenarios introduced in Section II.

\section{A. Protections Ratio Measurements}

The interference protection ratio is the minimum value of wanted-to-unwanted signal ratio, usually expressed in decibels at the RF receiver input, such that a specific reception quality criterion is achieved at the receiver [13]. The reception quality criterion depends on the technology under study. The Picture Failure Point (PFP) criterion is used for second generation DTT systems (DVB-T2) [23]. It is defined as the minimum Carrier-to-Interference Ratio (CIR) value that guarantees that two out of three consecutive 20 second periods are free from picture artifacts [13]. An MPEG-2 TS (Transport Stream) video containing motion pictures was used in the tests. Results presented in this paper correspond to the mean value of three independent measures.

The testing set-up used for the measurements is based on the ITU recommendation ITU-R BT. 2215-4 [24], and it is shown in Fig. 3. It should be pointed out that all elements are linear devices. The DTT and LTE signals were generated using an R\&S SMU 200A vector signal generator with channel emulation option, and an Aeroflex SGD digital signal generator, respectively. An R\&S ZVRE vector network analyser, a 5BT-375/750-5-O/O band-pass filter, and a MTC C189VFF isolator were also used in the measurements. The signal power was measured in the frequency domain.

The wanted DTT signal is fixed to $-60 \mathrm{dBm}$ power, and the interfering LTE signal power is varied at steps of $0.1 \mathrm{~dB}$ until the quality criterion is accomplished. A Rice channel is used to model fixed DTT reception, whereas for portable indoor DTT reception a Rayleigh channel. The 20-path channels

\begin{tabular}{|c|c|c|}
\hline \multicolumn{3}{|c|}{ DTT SIGNAL } \\
\hline Reception type & PORTABLE INDOOR & FIXED OUTDOOR \\
\hline Standard & DVB-T2 & DVB-T2 \\
\hline Modulation & 64QAM & 256QAM \\
\hline Code Rate (CR) & $2 / 3$ & $2 / 3$ \\
\hline Guard Interval (GI) & $1 / 8$ & $1 / 128$ \\
\hline $\mathrm{FFT}^{(*)}$ & $16 \mathrm{KE}$ & $32 \mathrm{KE}$ \\
\hline Bit rate & 18.1 Mbps & 40.4 Mbps \\
\hline \begin{tabular}{cc} 
SNR & AWGN \\
$(\mathrm{dB})$ & RICE \\
\multicolumn{2}{c}{ RAYLin } \\
$(\mathrm{dB} \mu \mathrm{V} / \mathrm{m})$
\end{tabular} & $\begin{array}{l}13.6 \\
16.1 \\
17.9 \\
46.6\end{array}$ & $\begin{array}{c}18.1 \\
20 \\
22.1 \\
47.9\end{array}$ \\
\hline Bandwidth & $6 \mathrm{MHz}$ & $8 \mathrm{MHz}$ \\
\hline \multicolumn{3}{|c|}{ LTE SIGNAL } \\
\hline LINK TYPE & UPLINK (UL) & DOWNLINK (DL) \\
\hline Multiplex & SC-FDMA & OFDM \\
\hline Guard Interval (GI) & $\begin{array}{c}\text { 512, 1024, 1536, } \\
2048 \\
\text { (4.7 } \mu \text { s first symbol, } \\
5.2 \mu \text { sest) }\end{array}$ & 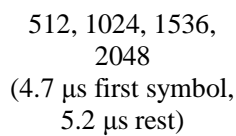 \\
\hline Bandwidth & $5,10,15,20 \mathrm{MHz}$ & 5, 10, 15, $20 \mathrm{MHz}$ \\
\hline Traffic Loading & 1, 10, 20 Mbps & Idle, $50 \%, 100 \%$ \\
\hline
\end{tabular}

* The letter $\mathrm{E}$ indicates the use of the extended carrier mode.
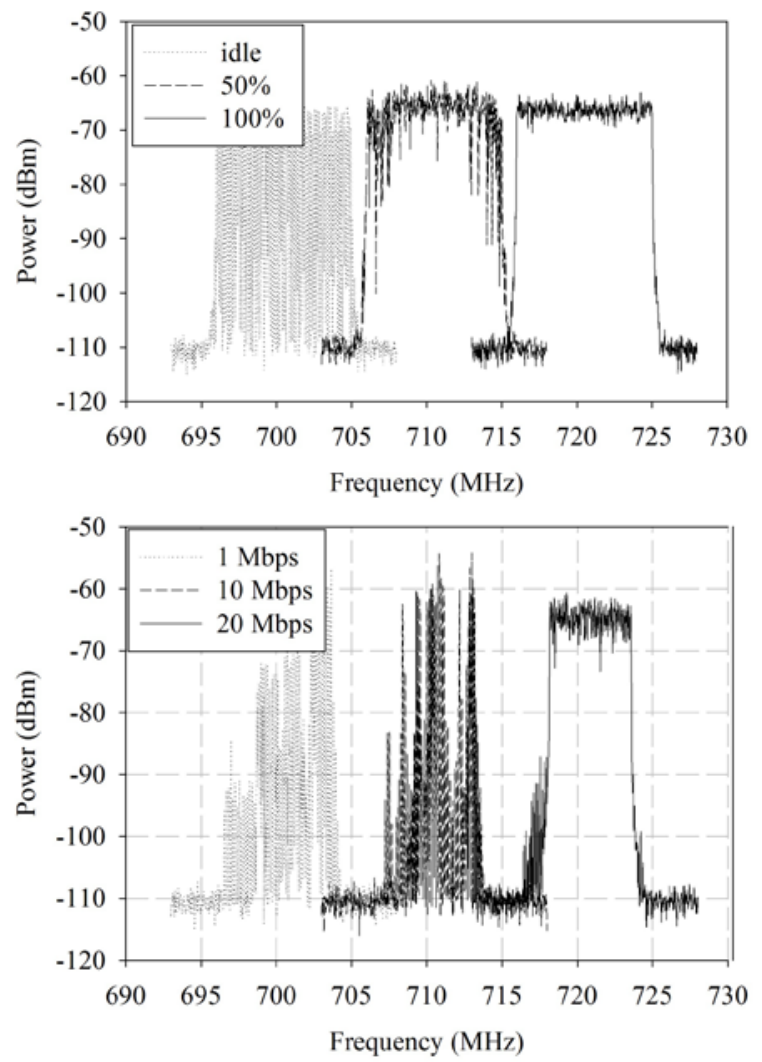

Fig. 4. Instantaneous spectrum of LTE DL (top) and UL (bottom) signals with $10 \mathrm{MHz}$ bandwidth for the different traffic loading used in the measurements. Resolution and video bandwidth are $30 \mathrm{kHz}$. Span is $15 \mathrm{MHz}$.

defined in DVB-T, and also used for DVB-T2, known as F1 and P1 channels have been used [25]. Three TV sets and three set-top boxes were used in the measurements. Results 
a)

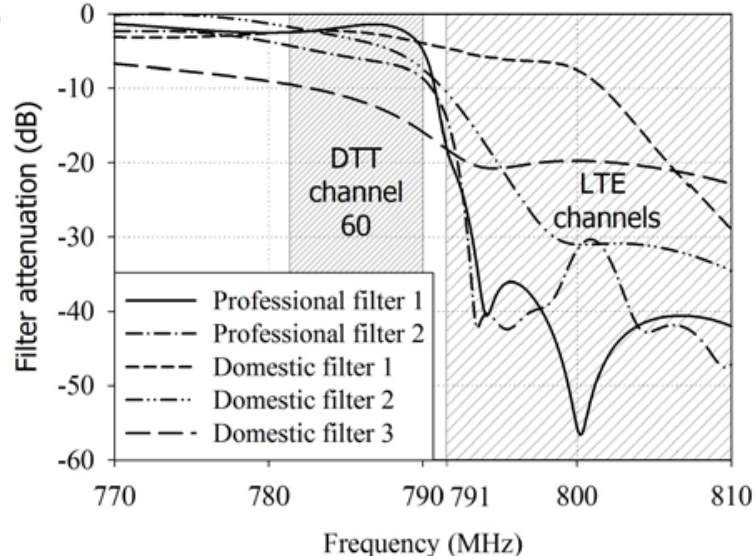

b)

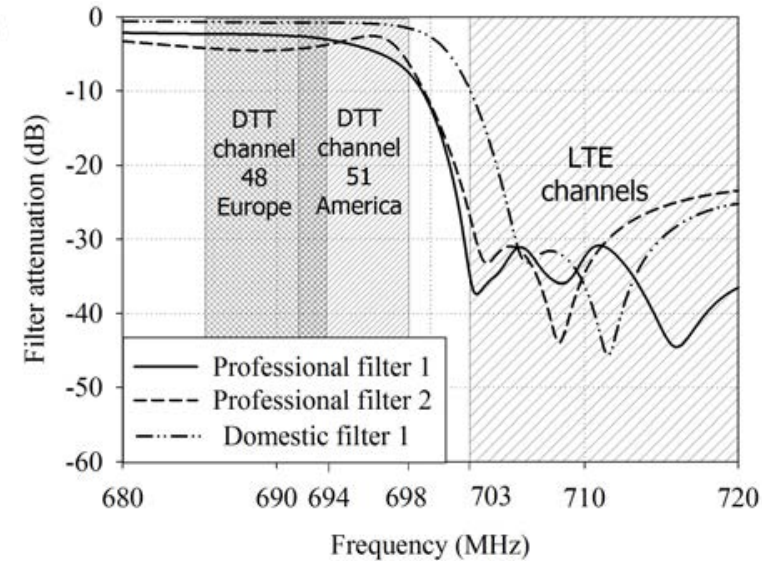

Fig. 5. Rejection level for domestic and professional filters for: a) $800 \mathrm{MHz}$ band and b) $700 \mathrm{MHz}$ band.

presented in this paper correspond to the second worst receiver in each setting, to cover a wide range of devices but not be limited by the worst receiver (usually, results are provided for 90 percentile of the receiver population [13]).

The characteristics of the DTT and LTE system parameters used in the measurements are shown in Table I. It should be noted that if another OFDM-based DTT technology, or another DVB-T2 transmission mode was used, the results obtained would be similar but adding an offset depending on the Carrier-to-Noise Ratio (CNR) difference. If different DTT signal bandwidths are considered, protection ratios for $8 \mathrm{MHz}$ are about $1 \mathrm{~dB}$ higher than for $6 \mathrm{MHz}$ due to the larger bandwidth.

Fig. 4 shows the spectrum of the LTE-DL and LTE-UL signals for different traffic loads used in measurements. The DL traffic is categorized as: idle (consisting mainly of synchronization and broadcast signals with occasional data), $50 \%$ loading (medium loading), and 100\% loading (all resource blocks continuously used). The LTE-UL traffic is categorized as: 1 Mbps (light loading where only a small number of resource blocks are used for some of the time), 10 Mbps (medium loading), and 20 Mbps (high loading). It should be pointed out that the LTE signals are compliant with the LTE-UE and LTE-BS emission masks defined in [27] and [28], respectively.

Two types of anti-LTE filters have been evaluated in the measurements, domestics and professionals. The performance of a filter is characterized by their rejection level at a given
TABLE II

LinK Budget Parameters. References [6] AND [26]

\begin{tabular}{|c|c|c|c|}
\hline \multicolumn{2}{|c|}{ DTT } & \multicolumn{2}{|c|}{ LTE } \\
\hline Parameter & Value & Parameter & Value \\
\hline $\begin{array}{l}\text { Equivalent Noise } \\
\text { Bandwidth }\end{array}$ & $\begin{array}{c}5.71 / 7.6 \\
\mathrm{MHz}\end{array}$ & BW & $\begin{array}{c}5 / 10 / 15 / 20 \\
\mathrm{MHz}\end{array}$ \\
\hline BW & $6 / 8 \mathrm{MHz}$ & \multicolumn{2}{|c|}{ BASE STATION } \\
\hline Noise Figure & $7 \mathrm{~dB}$ & $\begin{array}{l}\text { EIRP rural / urban } \\
\text { (Limited by noise) }\end{array}$ & 67 / $64 \mathrm{dBm}$ \\
\hline \multicolumn{2}{|c|}{ TRANSMISSION } & $\begin{array}{c}\text { EIRP urban } \\
\text { (limited by UL/DL } \\
\text { balancing) }\end{array}$ & $59 \mathrm{dBm}$ \\
\hline EIRP rural/urban & $\begin{array}{c}79.15 / 72.15 \\
\text { dBm }\end{array}$ & Noise Figure & $5 \mathrm{~dB}$ \\
\hline Antenna gain & $15 \mathrm{dBi}$ & Antenna Pattern & Directive \\
\hline $\begin{array}{l}\text { Antenna Height } \\
\text { rural/urban }\end{array}$ & $200 / 100 \mathrm{~m}$ & \multicolumn{2}{|c|}{ USER EQUIPMENT } \\
\hline Antenna Pattern & Directive & $\begin{array}{l}\text { Maximum transmit } \\
\text { power }\end{array}$ & $23 \mathrm{dBm}$ \\
\hline & & $\begin{array}{c}\text { Typical rural/urban } \\
\text { power }\end{array}$ & $2 /-9 \mathrm{dBm}$ \\
\hline \multicolumn{2}{|c|}{ RECEPTION } & Noise Figure & $9 \mathrm{~dB}$ \\
\hline $\begin{array}{l}\text { Antenna gain } \\
\text { outdoor/indoor }\end{array}$ & $9.15 / 2.15 \mathrm{dBi}$ & Antenna gain & $-3 \mathrm{dBi}$ \\
\hline Height & $10 \mathrm{~m}$ & Height & $1.5 \mathrm{~m}$ \\
\hline Pattern & Directive & Pattern & Omni \\
\hline
\end{tabular}

frequency. Fig. 5 shows the measured frequency response of the rejection level for the 8 different filters used in the measurements, classified as domestic and professional filters. Professional filters are cavity filters designed to be used in community antenna masts. Domestic filters are installed directly at the receiver side, and they are ceramic resonators (domestic filter 2 for $800 \mathrm{MHz}$ band) or LC filters (all other).

\section{B. Link Budget Analysis}

For the reference scenarios shown in Fig. 2, the LTE interference level over the DTT receiver can be calculated assuming typical link budget parameters, as shown in Table II.

For fixed outdoor DTT reception interfered by the LTE-UL, the link budget analysis yields, on one hand, the Adjacent Channel Interference Ratio (ACIR), which should be lower than the Adjacent Channel Selectivity (ACS) of the DTT receiver. If this criterion is not accomplished, an anti-LTE filter is necessary, and the analysis determines the minimum attenuation required by the filter. On the other hand, the link budget analysis also yields the required Adjacent-Channel Leakage Ratio (ACLR) of the LTE-UE to avoid interferences, which can be translated into the maximum allowed out-ofband (OOB) emission level. It should be noted that the higher is the ACLR, the more strict is the OOB emission level (i.e., a more restrictive LTE-UE spectrum mask is required).

For portable indoor DTT reception interfered by the LTEUL, the link budget analysis yields the minimum distance required between the LTE-UE and the DTT receiver to avoid interference. In this case, the lower the OOB emission level of the LTE-UE, the shorter the minimum allowed distance.

For fixed outdoor DTT reception interfered by the LTE-DL, 
the link budget analysis yields the protection distance between the LTE base station and the DTT rooftop antenna that avoids interference. The same analysis can be used for the case of portable indoor DTT reception interfered, although in this case the distance is much lower, due to the additional building penetration loss of the interfering LTE signal [14].

\section{1) LTE-UL as Interfering Link for Fixed DTT Reception}

First, the adjacent channel selectivity of the DTT receiver, $A C S_{R X}$, can be computed as:

$$
\operatorname{ACS}_{R X}=-10 \log _{10}\left(10^{-\left(P R_{(c o-c h}-P R_{a j j-c h}\right) / 10}-10^{-A C L R / 10}\right) \text {, }
$$

where $P R_{\text {co-ch }}$ and $P R_{a d j-c h}$ are the co-channel and adjacent channel protection ratios of the DTT receiver, respectively, and $A C L R$ is the adjacent-channel leakage ratio of the LTE signal generator used in the measurements (in our case, 75 $\mathrm{dB})$. The $A C S_{R X}$ can be improved using an external anti-LTE filter. Denoting $A C S_{\text {filter }}$ as the attenuation from the filter, the total ACS is given by:

$A C S_{\text {Total }}=A C S_{R X}+A C S_{\text {filter }}$

Then, the adjacent channel interference ratio generated by the LTE-UE, ACIR, can be derived from:

$$
A C I R=P R_{c o-c h}-P R_{a d j-c h-R E Q},
$$

where $P R_{a d j-c h-R E Q}$ is the required adjacent channel protection ratio, which can be obtained using:

$$
P R_{\text {adj-ch-REQ }}=P_{\mathrm{DTT}, \min }-I_{R X}+\delta \text {, }
$$

where $P_{D T T, \min }$ is the minimum power required at DTT receiver obtained from (5), $I_{R X}$ is the interference received at DTT receiver obtained from (7), and $\delta$ is the permitted level of desensitization that correspond to a $1 \mathrm{~dB}$ loss of sensibility of the receiver ( $\delta=5.78 \mathrm{~dB}$, [6]). The desensitization is the loss of the capability to decode the signals near the threshold due to spurious signals produced within the receiver.

$$
P_{\mathrm{DTT}, \min }=P_{N}+S N R_{\min } \text {, }
$$

where $S N R_{\min }$ is the required signal-to-noise ratio (SNR) of the used DTT mode (see Table I), and $\mathrm{P}_{\mathrm{N}}$ is the noise power obtained with:

$P_{N}=10 \log _{10}(K T B)+N F+30$

In (6), $K$ is the Boltzmann constant $\left(1.38 \times 10^{-23} \mathrm{~J} / \mathrm{K}\right), T$ is the ambient temperature $(290 \mathrm{~K}), B$ is the noise-equivalent bandwidth of the DTT receiver $(7.6 \mathrm{MHz}$ for $8 \mathrm{MHz}$ DTT channel bandwidth), and NF is the noise figure of the DTT receiver (a typical value is $7 \mathrm{~dB}$, [6]).

$I_{R X}=P_{U E, T X}+G_{U E, T X}-L$

In (7), $P_{U E, T X}$ is the maximum LTE-UE transmission power (23 dBm [6] ), $G_{U E, T X}$ is the LTE-UE antenna gain (typically -3 $\mathrm{dBi}[6])$, and $L$ is the coupling loss obtained using:

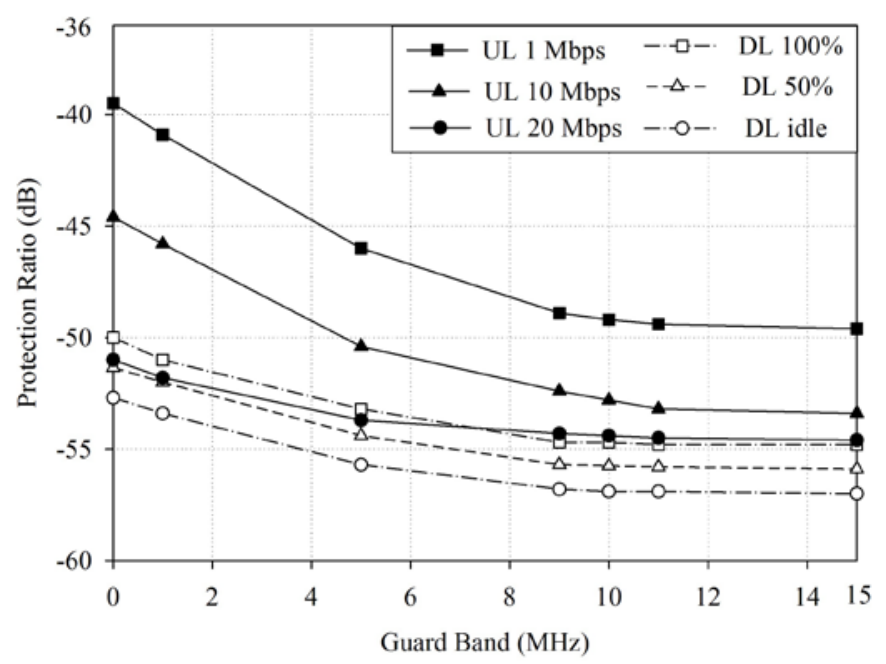

Fig. 6. Protection ratios for DVB-T2 portable indoor mode interfered by LTE-DL and LTE-UL with different traffic loads. LTE bandwidth $10 \mathrm{MHz}$ AWGN channel.

$L=F S L-G_{D T T, D I R}-G_{D T T, R X}+L_{B O D Y}$,

where FSL is the free space loss calculated at $22 \mathrm{~m}$ of horizontal separation between the LTE-UE and the DTT receiver antenna (as explained in Section II), $G_{D T T, R X}$ is the DTT receiver antenna gain including feeder loss (9. $15 \mathrm{dBi}$ [6]), $G_{D T T, D I R}$ is the DTT receiver antenna discrimination associated with the vertical radiation pattern at the worst horizontal separation distance $\left(-0.45 \mathrm{~dB}\right.$ [14]), and $L_{B O D Y}$ is the LTE-UE body loss (6 dB [6]).

Finally, the required adjacent-channel leakage ratio of the LTE-UE, $A C L R_{R E Q}$, can be calculated as:

$A C L R_{R E Q}=-10 \log _{10}\left(10^{-\frac{P R_{c o-c h}-P R_{a j j-c j-R E Q}}{10}}-10^{-\frac{A C S_{\text {Total }}}{10}}\right)$

And the associated out-of-band emission of the LTE-UE, $O O B_{\max }$, can be obtained:

$O O B_{M a x}=P_{U E, T X}+G_{U E, T X}-A C L R_{R E Q}$

Typical values for the out-of-band emission power of the LTE-UE is $-65 \mathrm{dBm} / 8 \mathrm{MHz}$ [6].

\section{2) LTE-UL as Interfering Link for Indoor DTT Reception}

In this case, the minimum distance between the LTE-UE to the DTT receiver that avoids interference, $d_{\min }$, can be computed as:

$d_{\min }=10 \frac{147.56-20 \log _{10}(f)-G_{C G}+G_{W L}+L_{B O D Y}+G_{D T T, R X}}{20}$,

where $L_{B O D Y}$ is the body loss $(6 \mathrm{~dB}), G_{W L}$ is the wall penetration loss $(0 \mathrm{~dB}$ assuming that both LTE-UE and DTT receiver are in the same room), $G_{D T T, R X}$ is the DTT receiver antenna gain (2.15 $\mathrm{dBi}$ for portable reception), and $G_{C G}$ is the total coupling gain. It can be computed using:

$G_{C G}=P_{D T T, \min }+\delta-P R_{c 0-c h}-10 \log _{10}\left(10^{\frac{P_{T X}-A C S_{R X}}{10}}+10^{\frac{O O B_{V E}}{10}}\right)$,

where $O O B_{U E}$ is the out-of-band emission power of the UE. 


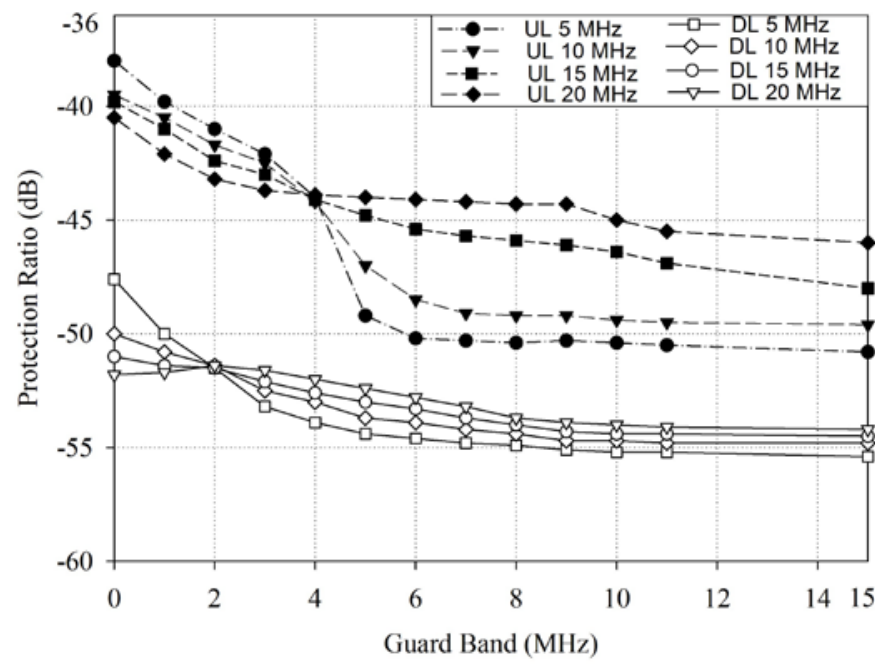

Fig. 7. Protection ratios for DVB-T2 portable indoor mode interfered by LTE-UL 1 Mbps and LTE-DL 100\% load with different LTE signal bandwidths. AWGN channel.

\section{3) LTE-DL as Interfering Link for Fixed Outdoor and Portable Indoor DTT Reception}

In these cases, the protection distance around the LTE-BSs, $d_{\min -B S}$, should be calculated. First, the minimum allowed propagation loss $L_{P}$ for the LTE-BS signal can be obtained using:

$$
L_{P}=E I R P_{B S}-G_{W L}+G_{D T T, R X}-P_{B S, T A R G E T} \text {, }
$$

where $E I R P_{B S}$ is the Equivalent Isotropic Radiated Power of the LTE-BS (59 dBm, see Table II), $G_{W L}$ of $8 \mathrm{~dB}$ for indoor reception and $0 \mathrm{~dB}$ for fixed reception, $G_{D T T, R X}$ of $9.15 \mathrm{dBi}$ fixed reception and $2.15 \mathrm{dBi}$ for indoor reception, and $P_{B S, T A R G E T}$ is the maximum BS interfering power allowed, which can be computed using:

$$
P_{B S, \text { TARGET }}=P_{\mathrm{DTT}, \min }-P R_{\text {adj-ch }}
$$

Once the minimum allowed $L_{P}$ is obtained, two results can be calculated: i) the protection distance $d_{\min -B S}$ using a representative path loss propagation model, and ii) the percentage of the LTE cell area interfered for DTT reception [6]. In the calculations the mean DTT received power should be considered, being naturally the worst-case when the LTE cell is deployed in an area where the DTT signal level is close to the threshold without interferences.

\section{Interference Protection Ratio Measurements}

\section{A. LTE interference link and traffic load influence}

Fig. 6 shows the DVB-T2 protection ratios as a function of the guard band in $\mathrm{MHz}$ for different traffic loads for LTE-DL and LTE-UL, respectively. It should be noted that protection ratio values are negative. That means that the LTE signal can be e.g. $50 \mathrm{~dB}$ higher (for a protection ratio of $-50 \mathrm{~dB}$ ) than the wanted DTT signal at the input of the receiver. In Fig. 6, it can be seen that the LTE-UL generates more interference than the LTE-DL. The worst-case protection ratios are approximately $10 \mathrm{~dB}$ less restrictive.

In Fig. 6 we can also observe that the most interfering LTE-

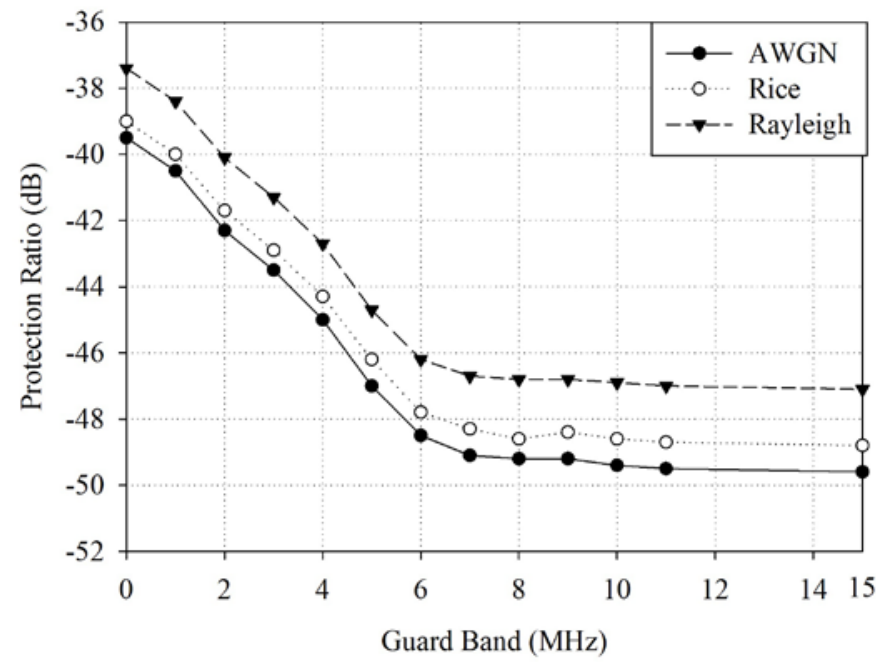

Fig. 8. Protection ratios for DVB-T2 portable indoor mode interfered by LTE-UL 1 Mbps for different channel models. LTE bandwidth $10 \mathrm{MHz}$.

TABLE III

IMPROVEMENT IN PROTECTION RATIOS (dB) FOR DVB-T2 INTERFERED BY

\begin{tabular}{|c|c|c|c|c|c|}
\hline \multicolumn{6}{|c|}{$800 \mathrm{MHz}$ Band Filters } \\
\hline \multirow{2}{*}{$\begin{array}{c}\text { LTE } \\
\text { Bandwidth } \\
\text { (MHz) }\end{array}$} & \multicolumn{2}{|c|}{ Professional Filters } & \multicolumn{3}{|c|}{ Domestic Filters } \\
\hline & $\begin{array}{c}\text { Filter } \\
1\end{array}$ & $\begin{array}{c}\text { Filter } \\
2\end{array}$ & $\begin{array}{c}\text { Filter } \\
1\end{array}$ & $\begin{array}{c}\text { Filter } \\
2\end{array}$ & $\begin{array}{c}\text { Filter } \\
3\end{array}$ \\
\hline 5 & 12.5 & 12.4 & 2.9 & 11.2 & 10.1 \\
\hline 10 & 15.6 & 15.6 & 3.8 & 13.4 & 12.8 \\
\hline 15 & 18.7 & 18.8 & 6.7 & 17.1 & 16.7 \\
\hline 20 & 19.4 & 19.6 & 9.1 & 18.3 & 17.7 \\
\hline \multicolumn{6}{|c|}{$700 \mathrm{MHz}$ Band Filters } \\
\hline $\begin{array}{c}\text { LTE } \\
\text { Bandwidth } \\
\text { (MHz) }\end{array}$ & $\begin{array}{c}\text { Filter } \\
1\end{array}$ & $\begin{array}{c}\text { Filter } \\
2\end{array}$ & & $\begin{array}{c}\text { Filter } \\
1\end{array}$ & \\
\hline 5 & 12.6 & 12.7 & & 11.4 & \\
\hline 10 & 15.7 & 15.8 & & 13.8 & \\
\hline 15 & 18.5 & 18.4 & & 16.6 & \\
\hline 20 & 19.5 & 19.4 & & 17.6 & \\
\hline
\end{tabular}
LTE-UL 1 MBPS AND 5 MHz BAND GUARD WITH ANTI-LTE FILTERS

UL signal is the one with the lightest loading (i.e., $1 \mathrm{Mbps}$ ). Lighter loads imply significantly larger time variations in the signal waveform, and hence worse interference protection ratios in general. In Fig. 4, it can be seen that the LTE signal for this traffic load does not resemble white noise. For the DL, the worst interference is for full load. This is due to the OFDM modulation, in which the higher the load, the higher the power level.

\section{B. DTT and LTE bandwidth influence}

Fig. 7 shows the DVB-T2 protection ratios for both LTEDL and LTE-UL, for the worst LTE traffic conditions identified in Fig. 6. For different LTE signal bandwidths, the worst protection ratio depends on the guard band between technologies. Regarding to LTE-UL interferences, for guard bands lower than $4 \mathrm{MHz}$, LTE signals with smaller bandwidths than $5 \mathrm{MHz}$ cause more interference. However, if 


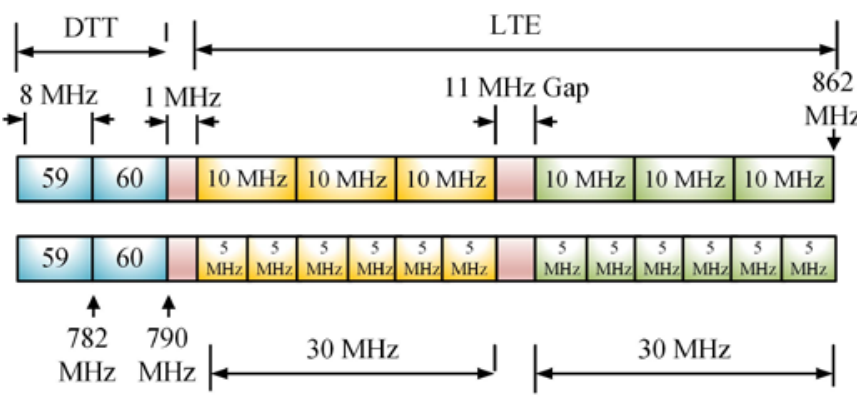

Fig. 9. Possible LTE channelizations in the $800 \mathrm{MHz}$ band (first digital dividend) in Europe.

the guard band increases, signals with larger bandwidth are more interfering. For LTE-DL there is also an inflexion point, but at $4 \mathrm{MHz}$ of guard band. Those behaviors are due that the occupied LTE bandwidth is $90 \%$ of the nominal bandwidth [27], and hence there is an additional guard band that is 0.25 , $0.5,0.75$, and $1 \mathrm{MHz}$ for 5, 10, 15 and $20 \mathrm{MHz}$ LTE channel bandwidth, respectively. This effect is significant for small guard bands, but not for long enough guard bands, where the LTE signal bandwidth is the dominating effect. The higher temporal variability of the LTE-UL signals cause that the effect of the intrinsic guard band of LTE signals disappears earlier than for LTE-DL signals (at $2 \mathrm{MHz}$ instead of $4 \mathrm{MHz}$ guard band).

Regarding the DTT signal bandwidth influence, presented results in this section are for $6 \mathrm{MHz}$ (DVB-T2 portable reception mode, see Table II). The use of $8 \mathrm{MHz}$ bandwidth would result in a degradation of about $1 \mathrm{~dB}$ in the protection ratios due to increased noise bandwidth.

\section{Type of DTT Reception}

All previous results have been obtained considering a Gaussian channel. Fig. 8 shows the protection ratios for LTEUL for Gaussian, Rice and Rayleigh channels. It can be observed that the difference is similar to the CNR thresholds shown in Table I. That is, the protection ratio values increase for realistic channel models.

\section{Anti-LTE filters}

Table III shows an improvement of up to $13 \mathrm{~dB}$ using domestic LTE filters at the DTT receiver, and about $15 \mathrm{~dB}$ using professional LTE filters for $10 \mathrm{MHz}$ LTE spectrum blocks and $5 \mathrm{MHz}$ guard band. The improvement is higher the higher is the LTE signal bandwidth. If the DL is the interfering signal the improvement in the PRs will be similar. For different guard bands the behavior of filters change depending on the filter response, so for lowers guard band the improvement of the protection ratios are lower than for large guard bands.

\section{COEXISTENCE IN THE $800 \mathrm{MHz}$ BAND}

The coexistence in the $800 \mathrm{MHz}$ band is representative of Europe (ITU Region 1), characterized mostly with rooftop DTT reception [29]. The critical coexistence case is then LTE DL interfering fixed rooftop DTT reception, see Fig. 2(a).

Fig. 9 shows the band plan of the $800 \mathrm{MHz}$ band with two possible LTE channelizations, using 5 and $10 \mathrm{MHz}$ spectrum
TABLE IV

PRotection RATIOS (dB) FOR THE 800 MHZ BAND IN EUROPE

\begin{tabular}{ccc}
\hline \hline $\begin{array}{c}\text { DTT } \\
\text { Channel }\end{array}$ & $\begin{array}{c}\text { LTE } \\
\text { Channelization 1 }\end{array}$ & $\begin{array}{c}\text { LTE } \\
\text { Channelization 2 }\end{array}$ \\
\hline \hline 58 & -48.8 & -49.7 \\
59 & -48.2 & -49.4 \\
60 & -39.5 & -38.8 \\
\hline
\end{tabular}

TABLE V

PRotection Distance BETWEen LTE-BS AND DVB-T2 RECEIVERs, URBAN

\begin{tabular}{ccccccc}
\multicolumn{7}{c}{ Without } \\
\hline \hline & \multicolumn{2}{c}{ Filter } & \multicolumn{2}{c}{$\begin{array}{c}\text { With } \\
\text { Domestic } \\
\text { Filter }\end{array}$} & \multicolumn{3}{c}{$\begin{array}{c}\text { With } \\
\text { Professional } \\
\text { Filter }\end{array}$} \\
\hline \hline $\begin{array}{c}\text { DTT field } \\
\text { strength } \\
(\mathrm{dB} \mu \mathrm{V} / \mathrm{m})\end{array}$ & $\begin{array}{c}\text { Rmin } \\
(\mathrm{km})\end{array}$ & $(\%)$ & $\begin{array}{c}\text { Rmin } \\
(\mathrm{km})\end{array}$ & $(\%)$ & $\begin{array}{c}\text { Rmin } \\
(\mathrm{km})\end{array}$ & $(\%)$ \\
\hline Threshold & 1.49 & 55.2 & 0.59 & 21.9 & 0.50 & 18.5 \\
$+10 \mathrm{~dB}$ & 0.73 & 27 & 0.27 & 10 & 0.24 & 8.9 \\
$+20 \mathrm{~dB}$ & 0.34 & 12.6 & 0.13 & 4.8 & 0.11 & 4.1 \\
\hline
\end{tabular}

blocks. It should be noted that there is only $1 \mathrm{MHz}$ guard band between 4G LTE and DTT. In our study we consider the last three DTT channels: channel 58 (from 766 to $774 \mathrm{MHz}$ ), channel 59 (from 774 to $782 \mathrm{MHz}$ ) and channel 60 (from 782 $\mathrm{MHz}$ to $790 \mathrm{MHz}$ ).

Table IV shows the protection ratios for the two LTE channelizations considered. Measurements have been performed for the fixed outdoor DVB-T2 mode and LTE downlink configuration shown in Table I with 100\% traffic load. In the Table IV it can be observed that the protection ratio for channel 59 is about $9 \mathrm{~dB}$ better than for channel 60 . Also, using LTE channels of $5 \mathrm{MHz}$ increases the interference by about $1 \mathrm{~dB}$ compared to using blocks of $10 \mathrm{MHz}$. Regarding the use of filters, domestic and professional filters improve the protection ratio by 13 and $15 \mathrm{~dB}$, respectively (see Table III).

Table V shows the protection distance from the LTE-BS to avoid interference for the cases considered in the previous sub-section. Recall that presented results are worst case in the sense that it is assumed that the DTT rooftop antenna is oriented to the LTE-BS and there is no angular discrimination. The protection distance values depend on the average DTT signal level in the LTE cell.

The reception threshold for the DVB-T2 mode used is 48 $\mathrm{dB} \mu \mathrm{V} / \mathrm{m}$. If an LTE-BS is deployed at the edge of the DTT coverage area, assuming that the LTE EIRP is $59 \mathrm{dBm}$, and using LTE spectrum blocks of $10 \mathrm{MHz}$, the protection distance is $1.49 \mathrm{~km}$ using the Okumura-Hata path loss propagation model [30], [31]. The minimum DTT field strength that guarantees that no interference occurs without any filter is $99 \mathrm{~dB} \mu \mathrm{V} / \mathrm{m}$. The use of domestic filters, assuming $13 \mathrm{~dB}$ improvement of the protection ratio (see Table III), restricts the interference from $1.49 \mathrm{~km}$ down to $585 \mathrm{~m}$. The use of professional filters assuming $15 \mathrm{~dB}$ improvement of the protection ratio further reduces the protection distance down to $502 \mathrm{~m}$. 

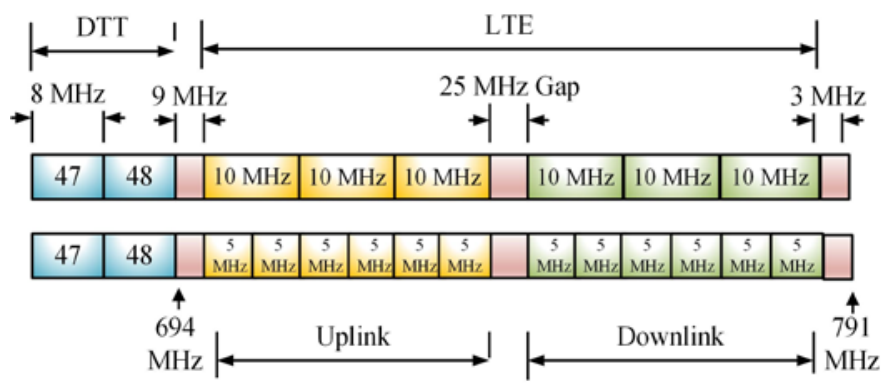

Fig. 10. Possible LTE channelizations in the $700 \mathrm{MHz}$ band (second digital dividend) in Europe.

\section{COEXISTENCE IN THE $700 \mathrm{MHz}$ BAND}

\section{A. Fixed Outdoor DTT Reception}

Fig. 10 shows the band plan of the $700 \mathrm{MHz}$ in Europe with two possible LTE channelizations, using 5 and $10 \mathrm{MHz}$ spectrum blocks. Compared to the $800 \mathrm{MHz}$ band (Fig. 9), the difference is that the guard band is $9 \mathrm{MHz}$ instead of $1 \mathrm{MHz}$, and that the LTE uplink is adjacent to the DTT transmissions instead of the LTE downlink. In this case, the critical coexistence scenario is then LTE-UL interfering fixed rooftop DTT reception, see Fig. 2(c).

Table VI shows the protection ratios for the last three DTT channels (channel 47, from 678 to $686 \mathrm{MHz}$, channel 48, from 686 to $694 \mathrm{MHz}$, and channel 49, from 678 to $686 \mathrm{MHz}$ ) for the two LTE channelizations considered. Measurements were performed using the DVB-T2 fixed outdoor mode and the LTE uplink with 1 Mbps mode shown in Table I.

Due to the increase of the guard band, from $1 \mathrm{MHz}$ to 9 $\mathrm{MHz}$, the protection ratios are $5 \mathrm{~dB}$ less restrictive than in 800 $\mathrm{MHz}$ band, even if the LTE-UL is more interfering than the LTE-DL. The use of domestic and professional filters improve the protection ratios in 13 and $15 \mathrm{~dB}$, respectively (see Table III). From the table it is interesting to note that the LTE channelization using $5 \mathrm{MHz}$ spectrum blocks generates less interference. This is coherent with the results presented in Section IV-B, in which it can be seen that for LTE-UL interferences, if the guard band is lower than $4 \mathrm{MHz}$, larger LTE spectrum blocks reduce the interferences. Smaller LTE spectrum blocks reduce the interference level for guard bands upper than $4 \mathrm{MHz}$.

Regarding the link budget analysis described in Section IIIB- 1 , assuming a protection ratio of $-42 \mathrm{~dB}$ (DTT channel 48, LTE channelization $10 \mathrm{MHz}$, see Table VI), we get an ACS of the DTT receiver of $61.18 \mathrm{~dB}$, and an ACIR of $69.06 \mathrm{~dB}$. Hence, interferences would occur unless a filter with $9 \mathrm{~dB}$ rejection is used. Domestic filters for $700 \mathrm{MHz}$ band offers around $20 \mathrm{~dB}$ rejection for the first LTE channel (see Fig. 5(b)), and thus a domestic filter would be enough to avoid interferences. It should be noted that a filter is also necessary to protect DTT channel 47 and 46, because the difference in the protection ratio is less than $9 \mathrm{~dB}$.

Regarding the ACLR and OOB emissions requirements for the LTE-UE, assuming $9 \mathrm{~dB}$ filter rejection, the required ACLR is $75.49 \mathrm{~dB}$, and the OOB emission level is -55.5 $\mathrm{dBm} / 8 \mathrm{MHz}$. If a domestic filter is assumed (20 $\mathrm{dB}$ rejection) the required ACLR would be relaxed down to $69.33 \mathrm{~dB}$, and the OOB emission level to $-49.3 \mathrm{dBm} / 8 \mathrm{MHz}$.
TABLE VI PROTECTION RATIOS (dB) FOR THE 700 MHz BAND IN EUROPE

\begin{tabular}{ccc} 
DTT Channel & LTE Channelization 1 & LTE Channelization 2 \\
\hline 46 & -44.2 & -44.7 \\
47 & -43.3 & -44.3 \\
48 & -42.6 & -43.8 \\
\hline
\end{tabular}

TABLE VII

MINIMUM LTE-UE REQUIREMENT TO AVOID INTERFERENCES OVER DTT, $700 \mathrm{MHZ}$ BAND EUROPA, OUTDOOR SCENARIO

\begin{tabular}{cc|ccc}
\hline \hline $\begin{array}{c}\text { LTE-UE } \\
\text { transmission } \\
\text { power }\end{array}$ & $\begin{array}{c}\text { DTT } \\
\text { Received } \\
\text { Power }\end{array}$ & $\begin{array}{c}\text { Filter } \\
\text { rejection } \\
(\mathrm{dB})\end{array}$ & $\begin{array}{c}\text { LTE- } \\
\text { UE } \\
\text { ACLR } \\
(\mathrm{dB})\end{array}$ & $\begin{array}{c}\text { LTE-UE OOB } \\
\text { emission level } \\
(\mathrm{dBm} / 8 \mathrm{MHz})\end{array}$ \\
\hline $\begin{array}{c}\text { Max Power: } \\
23 \mathrm{dBm}\end{array}$ & $\begin{array}{c}\text { Threshold } \\
+10 \mathrm{~dB}\end{array}$ & 9 & 75.5 & -55.5 \\
$\begin{array}{c}\text { Rural: } \\
\text { Threshold }\end{array}$ & 0 & 72.8 & -52.8 \\
Urban: & Threshold & 0 & 49.3 & -49.3 \\
$-9 \mathrm{dBm}$ & $+10 \mathrm{~dB}$ & 0 & 40.9 & -40.9 \\
& & 0 & 28.9 & -49.1 \\
& & 0 & & -40.9
\end{tabular}

It should be noted that this results are for the worst case, i.e. LTE-UE transmitting at maximum power $(23 \mathrm{dBm})$ and with DTT received power equal to the signal threshold (-78.2 $\mathrm{dBm})$. In a realistic scenario, the LTE-UEs rarely transmit at maximum power, and the received DTT power is higher than the threshold unless at the edge of the DTT coverage area. Table VII shows the required ACLR and OOB emission level of the LTE-UE for different transmit powers and DTT received power levels.

The values obtained in our study shown in Table VII are in general lower (i.e., more strict) than the thresholds proposed by 3GPP and CEPT, and are in good alignment with the existing protection requirements (see reference [20] for a comparison of the requirements in terms of LTE-UE OOB emissions proposed by the different entities). For an LTE-UE OOB emission of $-56 \mathrm{dBm} / 8 \mathrm{MHz}$, maintaining the broadcasters' existing protection levels, a domestic filter would still be needed in order to avoid interference over the last DTT channel 48 in the worst-case scenario. However, the filter would not be needed if:

- $\quad$ LTE-UE transmission power is lower than $15 \mathrm{dBm}$. For typical powers for rural and urban environments ( 2 and $-9 \mathrm{dBm}$, respectively) the filter is not needed.

- The DTT received power is higher than $-70 \mathrm{dBm}$.

\section{B. Portable Indoor DTT Reception}

Fig. 11 shows two possible LTE channelizations for the 700 $\mathrm{MHz}$ band in America (ITU Region 2) using the APT (AsiaPacific Telecommunity) band plan. In this case, the guard band is $5 \mathrm{MHz}$, and the interfering LTE link is again the uplink, as for fixed outdoor reception. It should be noted that the bandwidth of the DTT channels is $6 \mathrm{MHz}$ instead of 8 MHz. In America, the percentage of rooftop TV antennas is very limited, and hence most DTT networks target portable indoor reception. The critical coexistence scenario is then LTE-UL interfering portable indoor DTT reception, see Fig. 2(d). 

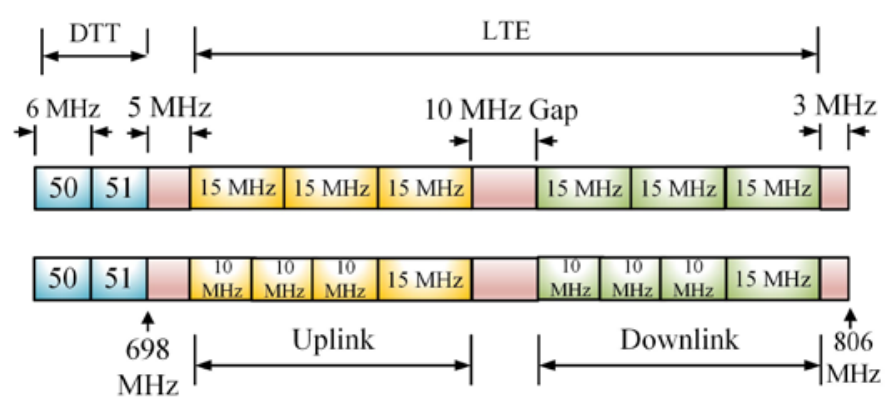

Fig. 11. Possible LTE channelizatios in the $700 \mathrm{MHz}$ band in America.

Table VIII shows the protection ratios for the two LTE channelizations shown in Fig. 10, and also $5 \mathrm{MHz}$ spectrum blocks. Measurements have been performed for the portable indoor DVB-T2 mode and the LTE uplink with 1 Mbps load mode in Table I. Since the guard band is $5 \mathrm{MHz}, 15 \mathrm{MHz}$ blocks generate more interference (see Fig. 7). For the last DTT channel 51, the protection ratios improve approximately $2 \mathrm{~dB}$ and $5 \mathrm{~dB}$ for spectrum blocks of $10 \mathrm{MHz}$ and $5 \mathrm{MHz}$, respectively. It should be pointed out that results shown are valid for other DTT OFDM-based technologies with a CNR requirement of about $18 \mathrm{~dB}$ in Rayleigh channel. The difference of using e.g. ISDB-Tb compared to DVB-T2 is that the capacity would be smaller. For the considered CNR, about $33 \%$ less (16QAM 3/4 instead of 64QAM 2/3).For the case of ATSC 3.0, the same PR would be valid for a higher capacity, since it will outperform the spectral efficiency of DVB-T2 [22].

The critical link budget case is when the LTE-UE and the DTT receiver are in the same room and therefore there are no wall penetration losses. For the maximum transmission power, the minimum distance is $7.76 \mathrm{~m}$ even for the existing required OOB level, and $5.79 \mathrm{~m}$ for a transmit power of $-9 \mathrm{dBm}$. The use of a commercial filter would reduce the protection distance down to $5.82 \mathrm{~m}$ for the maximum transmission power, but the distances are maintained for $-9 \mathrm{dBm}$ LTE-UE transmit power, respectively. To avoid interferences, the DTT received signal level to allow maximum transmit power would be $55 \mathrm{~dB}$ above threshold for the maximum LTE-UE transmit power, and $53 \mathrm{~dB}$ for $-9 \mathrm{dBm}$.

\section{CONCLUSIONS}

This paper has investigated potential coexistence issues between DTT and 4G LTE networks in the $700 \mathrm{MHz}$ and the $800 \mathrm{MHz}$ UHF bands by measuring interference protection ratios in laboratory conditions and performing link budget analyses. Both fixed outdoor and portable indoor DTT reception scenarios have been considered; and the impact of the guard band and the use of anti-LTE filters have been studied, together with different LTE signal parameters such as traffic load, bandwidth, and interfering link (uplink and downlink). Lighter loads imply significantly larger time variations in the signal waveform, and hence worse interference protection ratios in general (up to almost $10 \mathrm{~dB}$ ), and that is the reason why the LTE uplink generates more interference than the downlink. The use of anti-LTE commercial and professional (for rooftop installations) filters
TABLE VIII

PROTECTION RATIOS (dB) FOR THE 700 MHz BAND IN AMERICA

\begin{tabular}{|c|c|c|c|}
\hline $\begin{array}{c}\text { DTT } \\
\text { Channel }\end{array}$ & $\begin{array}{c}\text { LTE } \\
\text { Channelization } 1\end{array}$ & $\begin{array}{c}\text { LTE } \\
\text { Channelization } 2\end{array}$ & $\begin{array}{c}\text { LTE } \\
\text { Channelization } 3 \\
(5 \mathrm{MHz})\end{array}$ \\
\hline 49 & -46.2 & -47.8 & -49.2 \\
\hline 50 & -44.1 & -47.6 & -48.2 \\
\hline 51 & -41.8 & -43.1 & -46.9 \\
\hline
\end{tabular}

can improve the interference protection ratios by $13 \mathrm{~dB}$ and 15 $\mathrm{dB}$, respectively.

Our results show that it is very difficult to avoid interferences in the worst-cases (e.g., maximum LTE transmit power, received DTT signal power just above threshold, interfering LTE base station in line of sight with the DTT rooftop antenna, LTE user equipment in the same room than a portable DTT receiver, etc.), being specially critical the coexistence of portable indoor DTT reception with LTE in the $700 \mathrm{MHz}$ band, since the LTE uplink is placed in the lower part of band. In this case, high quality standards in terms of the out-of-band emissions for the LTE-UEs are recommended. Naturally, the LTE interferences depend on the level of the useful DTT signals, and hence potential coexistences issues have to be studied case by case, especially for DTT networks dimensioned for fixed rooftop reception.

\section{REFERENCES}

[1] W. Sami, "How Can Mobile and Broadcasting Networks use Adjacent Bands," Digital Dividend 2012.

[2] DigiTAG, "Update on the Use of the $700 \mathrm{MHz}$ Band in Europe," Newsletter, March, 2015.

[3] P. Lamy, "Results of the Work of the High Level Group on the Future Use of the UHF Band (470-790 MHZ)," Report to the European Commission, Sept. 2014.

[4] D. Gomez-Barquero and M. W. Caldwell, "Broadcast Television Spectrum Incentive Auctions in the U.S.: Trends, Challenges and Opportunities,” IEEE Comm. Mag., vol. 53, no. 7, pp. 50-56, July 2015.

[5] DIGITALEUROPE, "Recommendations on DTT Interference Avoidance from LTE Transmissions,” Recommendation, Brussels, Dec. 2012.

[6] CEPT, "The Identification of Common and Minimal (least restrictive) Technical Conditions for 790 - $862 \mathrm{MHz}$ for the Digital Dividend in the European Union," CEPT Report 30, Oct. 2009.

[7] DVB SB2122, "Study on Specification and Use of in-line Filters to Reduce Interference in Broadcast Bands from Mobile Base Stations," DVB White Paper, Mar. 2014.

[8] A. De Vita, D. Milanesio, B. Sacco, A. Scotti, "Assessment of Interference to the DTT Service Generated by LTE Signals on Existing Head Amplifiers of Collective Distribution Systems: A Real Case Study,” IEEE Trans. Broadcast., vol. 60, no.2, pp.420-429, June 2014.

[9] L. Polak, et al., "Mobile Communication Networks and Digital Television Broadcasting Systems in the Same Frequency BandsAdvanced Co-Existence Scenarios,” Radioengineering, vol. 23, no. 1, pp. 375-386, April 2014.

[10] L. Polak, et al., "Study of coexistence between indoor LTE femtocell and outdoor-to-indoor DVB-T2-Lite reception in a shared frequency band," EURASIP Journal on Wireless Communications and Networking, vol. 2015, no. 114, Apr. 2015.

[11] L. Polak, et al., "Exploring and measuring the co-existence between LTE and DVB-T2-Lite services," Proc. 36th International Conference Telecommunications and Signal Processing (TSP), pp. 316-320, Rome (Italy), 2013.

[12] G. Baruffa, M. Femminella, F. Mariani, and G. Reali, "Protection Ratio and Antenna Separation for DVB-T/LTE Coexistence Issues," IEEE Communications Letters, vol.17, no.8, pp.1588-1591, Aug. 2013. 
[13] ITU-R, "Planning Criteria, Including Protection Ratios, for Second Generation of Digital Terrestrial Television Broadcasting Systems in the VHF/UHF Bands,” Recommendation ITU-R BT.2033, Jan. 2013.

[14] "WRC-15 agenda item 1.2: Lower Edge of Mobile Allocation and Adjacent Band Compatibility”. CPG-PTD (13)010, Jan. 2013.

[15] M. Fuentes, C. Garcia-Pardo, E. Garro, D. Gomez-Barquero, and N. Cardona. "Coexistence of digital terrestrial television and next generation cellular networks in the $700 \mathrm{MHz}$ band," IEEE Wireless Communications, vol. 21, no.6, pp. 63-69, Dec. 2014.

[16] D.-H. Kim, S.-J. Oh, and J.S. Woo, "Coexistence Analysis between IMT System and DTV System in the $700 \mathrm{MHz}$ Band,” Proc. International Conference on ICT Convergence (ICTC), Jeju, Korea (South), 2012.

[17] SET, "Pruebas de Interferencia de la Señal LTE en la Recepción de TV Digital en la Banda De UHF,” Feb. 2014.

[18] ATDI, "Report for GSMA on the Coexistence of ISDB-T and LTE", Nov. 2015.

[19] W. Li, J. Chen, H. Long, and B. Wu, "Performance and Analysis on LTE System under Adjacent Channel Interference of Broadcasting System," Proc. IEEE 12th International Conference on Computer and Information Technology (CIT), pp. 290-294, Oct. 2012.

[20] EBU Fact sheet, “Protection of DTT from LTE 700,” Feb. 2015.

[21] I. Eizmendi, et al., "DVB-T2, the Second Generation of Terrestrial Digital Video Broadcasting System,” IEEE Trans. Broadcast., vol. 60, no. 2, pp. 258-271, June 2014.

[22] L. Michael and D. Gomez-Barquero, "Bit-Interleaved Coding and Modulation (BICM) for ATSC 3.0,” IEEE Transactions on Broadcasting, vol. 62, Part 1, no. 1, 2016.

[23] DIGITALEUROPE, "Standardized DVB-T2 RF specifications," White paper, Brussels, April 2012.

[24] ITU-R, "Measurements of protection ratios and overload thresholds for broadcast TV receivers,” Recommendation ITU-R BT.2215-4, November. 2014

[25] ETSI, “Digital Video Broadcasting (DVB); Implementation guidelines for a second generation digital terrestrial television broadcasting system (DVB-T2),” ETSI TS 102831 v1.2.1, Aug. 2012.

[26] ITU-R, "Reference Radiation Patterns of Omnidirectional, Sectoral and other Antennas in Point-to-Multipoint Systems for use in Sharing Studies in the Frequency Range from $1 \mathrm{GHz}$ to about $70 \mathrm{GHz}$," Recommendation ITU-R F.1336-3, May 2012.

[27] ETSI, "LTE; Evolved Universal Terrestrial Radio Access (E-U TRA); User Equipment (UE) radio transmission and reception,” ETSI TS 136 101, Jun. 2011.

[28] 3 GPP, “3rd Generation Partnership Project; Technical Specification Group Radio Access Network; Evolved Universal Terrestrial Radio Access (E-UTRA); Base Station (BS) radio transmission and reception,” 3GPP TS 36 104, Sep. 2015.

[29] David Gomez-Barquero (Ed.), "Next-Generation Mobile Broadcasting," CRC press, March 2013.

[30] Y. Okumura, E. Ohmohri, T. Kawano, and K. Fukada, "Field strength and its variability in VHF and UHF land-mobile radio service,” Rev. Electr. Commun. Lab., vol. 16, nos. 9-10, pp. 825-873, Sep. 1968.

[31] M. Hatay, "Empirical formula for propagation loss in land mobile radio services," IEEE Trans. Veh. Technol., vol.29, no.3, pp.317-325, Aug. 1980.

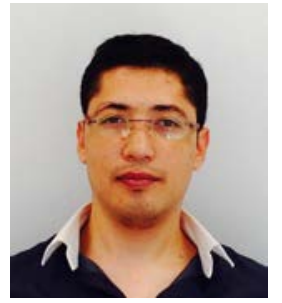

Jefferson Ribadeneira-Ramírez received the Electronic and Computation Engineering degree in 2008 from the Escuela Superior Politécnica de Chimborazo (ESPOCH), Riobamba, Ecuador. In 2010 he was recipient of a scholarship for studies of excellence, granted by the SENESCYT (Secretaría Nacional de Educación Superior, Ciencia, Tecnología e Innovación) of Ecuador. In 2013 he obtained the M. Sc. degree in Technologies Systems and Telecommunications networks from the Universitat Politecnica de Valencia (UPV), Valencia, Spain. Actually he work at Institute of Telecommunications and Multimedia Applications (iTEAM). He has been work in investigation and cooperation projects between iTEAM and the Colombian spectrum regulator (ANE). His research activities are focused on efficient spectrum management, DTT network planning, compatibility studies between DTT and other mobile technologies as LTE, as well the implementation of $4 \mathrm{G}$ communications in the Digital Dividend.

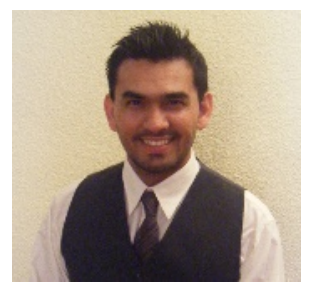

Gerardo Martínez received a double Telecommunications Engineer degree at Technical University of Valencia, Spain and Saint Thomas Aquinas University, Colombia. In 2013, he has finished a Master in Development of Mobile Communications Systems. More than 3 years of experience in the mobile communications, digital terrestrial television and electronic security systems fields. He has developed research activities and consulting providing recommendations on multiple projects from the initial design stages to planning, optimization, coexistence and deployment. Specialized in the latest telecommunications technologies like 4G-LTE (Long Term Evolution) mobile communications or DVB-T, DVB-T2 and ISDB-T digital terrestrial television (DTT) standards. His current research activities are focused on efficient spectrum management through the use of cognitive radio technologies.

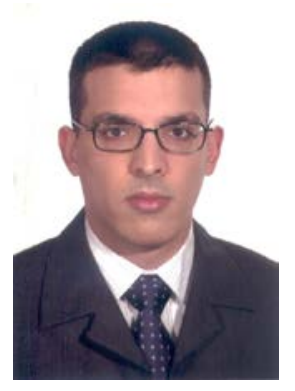

David Gómez-Barquero received the double M.Sc. degrees in telecommunications engineering from the Universitat Politecnica de Valencia (UPV), Spain, and the University of Gävle, Sweden, in 2004, the Ph.D. degree in telecommunications from the UPV in 2009; and he carried out a 2-year post-doc at the Fraunhofer Heinrich Hertz Institute, Germany. He is a Senior Researcher (Ramon \& Cajal Fellow) with the Institute of Telecommunications and Multimedia Applications, UPV, where he leads a research group working on next generation broadcasting technologies. He has hold visiting research appointments at Ericsson Eurolab, Germany, the Royal Institute of Technology, Sweden, the University of Turku, Finland, the Technical University of Braunschweig, Germany, the University Sergio Arboleda of Bogota, Colombia, and the New Jersey Institute of Technology, U.S.

Dr. Gómez-Barquero has been since 2008 actively participating in the European digital television standardization forum DVB in different topics such as upper layer forward error correction, DVB-T2, T2-Lite, and DVB-NGH. In 2013, he joined the U.S. digital television standardization forum ATSC to work on ATSC 3.0, acting as Vice-Chairman of the Modulation and Coding Ad-Hoc Group. He is the Editor of the book entitled Next Generation Mobile Broadcasting (CRC Press, 2013). 


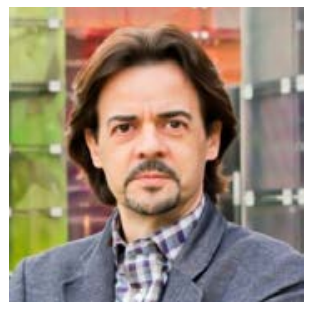

Narcís Cardona received the M.Sc. degree in Communications Engineering from the ETSI Telecommunications at the Polytechnic University of Catalunya in 1990, and the Ph.D. in Telecommunications from the Polytechnic University of Valencia in 1995. Since October 1990, he is with the Communications Department of the Polytechnic University of Valencia (UPVLC). Prof Cardona is in head of the Mobile Communications Group at the UPVLC, with 30 researchers including assistant professors \& research fellows. Additionally he is the Director of the Mobile Communications Master Degree (since 2006) and Vice-Director of the Research Institute of Telecommunications and Multimedia Applications (iTEAM) since 2004. Prof Cardona has led and participated to National research projects and to European projects, Networks of Excellence and other research forums, always in Mobile Communications aspects. At European scale, he has been Vice-Chairman of COST273 Action, Chair of the WG3 of COST2100 in the area of Radio Access Networks, and he is currently the Chairman of the EU Action COST IC1004 since May 2011. From his research work, Prof Cardona has authored eight patents, several books and above 160 research papers. His current areas of interest include mobile channel characterization; planning and optimization tools for cellular systems, RRM techniques applied to personal communications and broadcast cellular hybrid networks. 